for: Received honoraria for consultancies or speaker bureaus $(<10.000$ USD each) from the following pharmaceutical companies in the past 3 years: Ablynx, AbbVie, Astrazeneca-Medimmune, Biogen, Boehringer, Bristol-Myers Squibb, Eli-Lilly, EMD Serono, GlaxoSmithKline, Hoffmann-La Roche, Janssen, Merck, Novartis, Pfizer, R-Pharma, SanofiServier, Sinergie, Sobi and Takeda., Speakers bureau: Received honoraria for consultancies or speaker bureaus ( $<10.000$ USD each) from the following pharmaceutical companies in the past 3 years: Ablynx, AbbVie, Astrazeneca-Medimmune, Biogen, Boehringer, Bristol-Myers Squibb, Eli-Lilly, EMD Serono, GlaxoSmithKline, Hoffmann-La Roche, Janssen, Merck, Novartis, Pfizer, R-Pharma, SanofiServier, Sinergie, Sobi and Takeda. DOI: 10.1136/annrheumdis-2019-eular.7477

\section{THU0516 LONG-TERM SAFETY OF SUBCUTANEOUS TOCILIZUMAB ADMINISTRATION IN SYSTEMIC AND POLYARTICULAR JUVENILE IDIOPATHIC ARTHRITIS}

Fabrizio De Benedetti ${ }^{1}$, Nicolino Ruperto ${ }^{2}$, Athimalaipet Ramanan ${ }^{3}$, Ruben Cuttica ${ }^{4}$, Jennifer E. Weiss ${ }^{5}$, Michael Henrickson ${ }^{6}$, Heinrike Schmeling ${ }^{7}$, Jordi Anton ${ }^{8}$, Kirsten Minden ${ }^{9}$, Gerd Horneff ${ }^{10}$, Maria Luz Gámir Gámir ${ }^{11}$, Markus Hufnagel ${ }^{12}$, Wendy Douglass ${ }^{13}$, Chris Wells $^{13}$, Navita L. Mallalieu ${ }^{14}$, Alberto Martini ${ }^{2}$, Daniel J Lovell ${ }^{6}$, Hermine Brunner ${ }^{6} .{ }^{1}$ IRCCS Ospedale Pediatrico Bambino Gesù, Rome, Italy, ${ }^{2}$ Paediatric Rheumatology International Trials Organisation (PRINTO) Coordinating Centre, Genoa, Italy; ${ }^{3}$ Bristol Royal Hospital for Children, Bristol, United Kingdom; ${ }^{4}$ Hospital General de Niños Pedro Elizalde, Buenos Aires, Argentina; ${ }^{5}$ Hackensack University Medical Center, Hackensack, United States of America; ${ }^{6}$ Pediatric Rheumatology Collaborative Study Group (PRCSG), Cincinnati Children's Hospital Medical Center, Cincinnati, United States of America; ${ }^{7}$ Alberta Children's Hospital/University of Calgary, Calgary, Canada: ${ }^{8}$ Pediatric Rheumatology, Hospital Sant Joan de Déu, Universitat de Barcelona, Barcelona, Spain; ${ }^{9}$ Charité-Universitätsmedizin Berlin, Berlin, Germany; ${ }^{10}$ Asklepios Clinic Sankt Augustin, Sankt Augustin, and University Hospital of Cologne, Cologne, Germany; ${ }^{11}$ Hospital Ramon y Cajal Unidad de Reumatologia Pediatrica, Madrid, Spain; ${ }^{12}$ Department of Pediatrics and Adolescent Medicine, University Medical Center, Medical Faculty, University of Freiburg, Freiburg, Germany; ${ }^{13}$ Roche Products Ltd., Welwyn Garden City, United Kingdom; ${ }^{14}$ Roche Innovation Center, New York, United States of America

Background: Tocilizumab (TCZ) administered intravenously (IV) was effective for the treatment of polyarticular (p)JIA and systemic (s)JIA., ${ }^{1,2}$

Objectives: To evaluate the long-term safety and efficacy of subcutaneous (SC) TCZ in patients (pts) with pJIA or SJIA enrolled in a long-term extension (LTE) phase of two 52-week, open-label studies.

Methods: Pts aged 1-17 years received body weight (BW)-based TCZ SC: pJIA pts who failed/could not tolerate MTX received TCZ $162 \mathrm{mg}$ every 3 weeks for $\mathrm{BW}<30 \mathrm{~kg}$ or every 2 weeks (Q2W) for $\mathrm{BW}>30$ $\mathrm{kg}$; sJIA pts with inadequate response to NSAIDs and glucocorticoids received TCZ $162 \mathrm{mg} \mathrm{Q2W}$ for $\mathrm{BW}<30 \mathrm{~kg}$ or weekly for $\mathrm{BW} \geq 30 \mathrm{~kg}$. All pts discontinued biologic DMARDs (approximately $50 \%$ switched from TCZ IV to TCZ SC). After 52 weeks, pts continued BW-based TCZ in a separate LTE study; safety data (adverse events [AEs], serious AEs [SAEs]) in the LTE study to clinical cutoffs December 1, 2017 (pJIA), and February 28, 2018 (SJIA), are reported for all pts who received $\geq 1$ dose of TCZ SC and had $>1$ postdose safety assessment.

Results: Most pJIA $(n=44)$ and sJIA $(n=38)$ pts were female $(72.7 \%$ and $55.3 \%$ ) and white $(88.6 \%$ and $84.2 \%$ ); median (range) age was 9.0 (218) years. $A E$ rates (Table) were similar regardless of BW. Most AEs were grade 1 or 2 ; grade $\geq 3$ AEs were reported by $10 / 44(20.8 \%)$ pJIA pts and $4 / 38(10.5 \%)$ sJIA pts, most commonly nasopharyngitis (pJIA, 17/ 44 [38.6\%]; sJIA, 11/38 [28.9\%]). Other AEs reported in $\geq 15 \%$ of pts included arthralgia, gastroenteritis, cough, vomiting, diarrhea, pyrexia, headache, and oropharyngeal pain ( $\mathrm{JJIA}$ ) and upper respiratory tract infection, cough, pyrexia, arthralgia, and rash (sJIA). No opportunistic infections developed. Neutropenia AEs were reported by $6 / 44$ (13.6\%) pJIA pts and $7 / 38(18.4 \%)$ sJIA pts. SAEs occurred in $5 / 44$ (11.4\%) pJIA pts (furuncle, appendicitis, pneumonia, eye pain/headache, infectious mononucleosis) and $2 / 38$ (5.3\%) sJIA pts (pneumonia, craniocerebral injury from a fall); only pneumonia (pJIA) was considered treatment related. Neutralizing anti-TCZ antibodies developed in $2(4.7 \%)$ pJIA pts and no SJIA patients. No deaths were reported in the LTE study.

Conclusion: In this LTE study in children with PJIA or SJIA, SC TCZ continues to have an acceptable tolerability profile with no new safety concerns.
Abstract THU0516 -Table 1

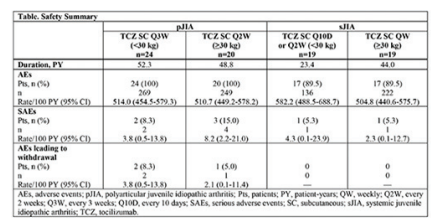

REFERENCES:

[1] Brunner HI et al. Ann Rheum Dis. 2015;74:1110-1117.

[2] 2. De Benedetti F et al. N Engl J Med. 2012;367:2385-2395.

Disclosure of Interests: Fabrizio De Benedetti Grant/research support from: Abbvie, SOBI, Novimmune, Roche, Novartis, Sanofi, Pfizer, Nicolino Ruperto Grant/research support from: The Gaslini Hospital, where NR works as full-time public employee, has received contributions (> 10.000 USD each) from the following industries in the last 3 years: BMS, EliLilly, GlaxoSmithKline, F Hoffmann-La Roche, Janssen, Novartis, Pfizer, Sobi. This funding has been reinvested for the research activities of the hospital in a fully independent manner, without any commitment with third parties., Consultant for: Received honoraria for consultancies or speaker bureaus (< 10.000 USD each) from the following pharmaceutical companies in the past 3 years: Ablynx, AbbVie, Astrazeneca-Medimmune, Biogen, Boehringer, Bristol-Myers Squibb, Eli-Lilly, EMD Serono, GlaxoSmithKline, Hoffmann-La Roche, Janssen, Merck, Novartis, Pfizer, RPharma, SanofiServier, Sinergie, Sobi and Takeda., Speakers bureau: Received honoraria for consultancies or speaker bureaus $(<10.000$ USD each) from the following pharmaceutical companies in the past 3 years: Ablynx, AbbVie, Astrazeneca-Medimmune, Biogen, Boehringer, BristolMyers Squibb, Eli-Lilly, EMD Serono, GlaxoSmithKline, Hoffmann-La Roche, Janssen, Merck, Novartis, Pfizer, R-Pharma, SanofiServier, Sinergie, Sobi and Takeda., Athimalaipet Ramanan Consultant for: AbbVie, UCB, Sobi, Eli Lilly, Speakers bureau: Speaker fees/honoraria from Abbvie, SOBI, Eli Lilly and UCB, Speakers bureau: AbbVie, UCB, Sobi, El Lilly, Ruben Cuttica Grant/research support from: Roche, Pfizer, Lilly, Bristol Myers Squibb, Novartis, Sanofi Aventis, UCB, Janssen., Consultan for: Roche, Pfizer, Lilly, Bristol Myers Squibb, Novartis, Sanofi Aventis, UCB, Janssen., Speakers bureau: Roche, Pfizer, Lilly, Bristol Myers Squibb, Novartis, Sanofi Aventis, UCB, Janssen., Jennifer E. Weiss: None declared, Michael Henrickson: None declared, Heinrike Schmeling Grant/ research support from: F. Hoffmann-La Roche Ltd, Jordi Anton Grant/ research support from: Grant/research support, consultant or speakers bureau from AbbVie, Alexion, Bristol-Myers Squibb, ChemoCentryx, Gebro, GlaxoSmithKline, Novartis, Novimmune, Pfizer, Roche, Sanofi and Sobi, Consultant for: Grant/research support, consultant or speakers bureau from AbbVie, Alexion, Bristol-Myers Squibb, ChemoCentryx, Gebro, GlaxoSmithKline, Novartis, Novimmune, Pfizer, Roche, Sanofi and Sobi, Speakers bureau: Grant/research support, consultant or speakers bureau from AbbVie, Alexion, Bristol-Myers Squibb, ChemoCentryx, Gebro, GlaxoSmithKline, Novartis, Novimmune, Pfizer, Roche, Sanofi and Sobi, Kirsten Minden Consultant for: AbbVie, Gerd Horneff: None declared, Maria Luz Gámir Gámir: None declared, Markus Hufnagel: None declared, Wendy Douglass Shareholder of: Roche, Employee of: Roche, Chris Wells Employee of: Roche Products Ltd, Navita L. Mallalieu Shareholder of: Roche, Employee of: Roche, Alberto Martini: None declared, Daniel J Lovell Consultant for: Consulting fees and/or honoraria from Astra Zeneca, Wyeth Pharma, Amgen, Abbott, Pfizer, F. Hoffmann-La Roche, Novartis, UBC, Takeda, GSK, Boehringer, and Celgene, Hermine Brunner Grant research support from: Bristol-Myers Squibb, Pfizer, Consultant for: Pfizer, Bristol-Myers Squibb, Janssen, Novartis, Lilly, Roche, GlaxoSmithKline, Sanofi, Speakers bureau: Novartis, Roche DOI: 10.1136/annrheumdis-2019-eular.5824 